\title{
Co-Pyrolysis Characteristics of Biomass and Coal under Different Mixing Modes
}

\author{
$\mathrm{Jia} \mathrm{Hao}^{1}$ and Qimin $\mathrm{Wang}^{2}$ \\ 1 Shenyang Institute of Engineering, Shenyang, China. \\ 2 Shenyang Municipal Key laboratory of Biomass Utilization, Shenyang Institute \\ of Engineering, Shenyang, China \\ Email:wangqm03@163.com
}

\begin{abstract}
Biomass and coal co-pyrolysis is one of most important reactions in the co-combustion and co-gasification of them. In order to study the interaction of biomass and coal in the co-pyrolysis process, thermo gravimetric experiments of them under different mixing modes were make. The mixed modes of biomass and coal include uniformly mix and stratified layout (coal in the upper) and stratified layout (biomass in the upper). The experimental results show that: the temperature of co-pyrolysis is lower than that of coal pyroly sis separately; the co-pyrolysis reaction velocity would be accelerated or debased, that depends on the biomass components and the mixing modes; the co-pyrolysis reaction velocity of coal and sawdust would be accelerated under the condition of uniformly mix; the others would be debased. The experimental results show also that: the reaction velocities of biomasses and coal co-pyrolysis always are less than those of separately pyrolysis. This study provides the important reference and theoretical basis for biomass and coal co-combustion and co-gasification.
\end{abstract}

Keywords: biomass, co-pyrolysis, mixing modes

\section{Introduction}

With the rapid development of economy and the consumption of fossil fuels, China's energy shortage is becoming more and more serious. The use of fossil energy has brought serious pollutions to the environment. As a renewable clean energy, biomass has broad prospects for development. Effective and comprehensive utilization of biomass energy is urgently needed. Biomass and coal co-gasification as a method for the efficient use of energy is increasingly getting the attention of research scholars at domestic and overseas. Vuthaluru [1] found that the co-pyrolysis temperature of coal and biomass is different from that of coal, and no obvious synergism was founded in co-pyrolysis process by the thermal analysis method. Collot etc [2] found that the volatile yield rate of co-gasification in the fixed bed was higher than the theoretical calculated value; meanwhile the volatile yield rate of co-gasification in the fluidized bed was equal to the theoretical calculated value. There was no positive interaction in co-pyrolysis experiments in fluidized bed. Kezhong Li etc [3] concluded that there was obvious synergism in coal and biomass (sorghum, rice straw) co-gasification, but there was no obvious synergism in cogasification with coal and pine, deliming sorghum, deliming straw. Brown etc [4] had studied the No.6 coal of Illinois and switch grass co-gasification, and did not find the obvious synergistic effect. From literatures, it can be founded that the interaction between biomass and coal dependents on the biomass types, mixing modes, particle sizes and so on. The paper studies the interaction of biomass and coal co-pyrolysis under different mixing modes in order to find out the interaction conditions with thermo gravimetric. 


\section{The Experimental Facilities and Experimental Contents}

\section{Experimental facilities:}

The major facility in the experiments is Switzerland Mettler-Toledo' s TGA/DSC thermo gravimetric analyzer. The system includes thermal gravimetric/differential thermal analyzer synchronization, the TGA balance and thermostatic bath $\left(22^{\circ} \mathrm{C} \pm 1{ }^{\circ} \mathrm{C}\right)$. The TGA carrier gas is nitrogen with a flow rate of $60 \mathrm{ml} / \mathrm{min}$. There are two same $\mathrm{Al} 2 \mathrm{O} 3$ crucibles. The sample is only placed in one crucible; the other is used as a reference.

\section{Experimental contents:}

The experimental samples include lignite, sawdust and cotton stalk. Biomass has been grinded with a high-speed multi-function mill (voltage $220 \mathrm{~V}$, power $650 \mathrm{~W}$, speed $22000 / \mathrm{min}$ ) before the experiment, and the particle size is less than $0.2 \mathrm{~mm}$. The coal particle size is less than $0.105 \mathrm{~mm}$. The experimental temperature ranges from $50^{\circ} \mathrm{C}$ to $1000^{\circ} \mathrm{C}$ and the heating rate is $40^{\circ} \mathrm{C} / \mathrm{min}$. In the TGA experiments, the biomass and coal were mixed by three modes, e.g. uniformly mixed mode, stratified layout modes (biomass in the upper) and stratified layout modes (coal in the upper). In any co-pyrolysis experiments, the weight of biomass occupied the $50 \%$ of total weight. The proximate analysis and ultimate analysis of experimental samples are shown in Table 1 and Table 2.

Table 1. Proximatel Analysis of Biomass and Coal

\begin{tabular}{ccccc}
\hline & \multicolumn{4}{c}{ Components/\% } \\
\cline { 2 - 5 } Sample & $\mathrm{M}_{\mathrm{ad}}$ & $\mathrm{A}_{\mathrm{ad}}$ & $\mathrm{V}_{\mathrm{ad}}$ & $\mathrm{FC}_{\mathrm{ad}}$ \\
lignite & 6.75 & 26.17 & 38.08 & 29.00 \\
$\begin{array}{c}\text { cotton } \\
\text { stalk }\end{array}$ & 8.41 & 3.81 & 68.28 & 19.50 \\
sawdust & 5.59 & 0.48 & 80.23 & 13.70 \\
\hline
\end{tabular}

Table 2. Ultimate Analysis of Biomass and Coal

\begin{tabular}{cccccc}
\hline \multirow{2}{*}{ Sample } & \multicolumn{5}{c}{ Components/\% } \\
\cline { 2 - 6 } & $\mathrm{C}_{\mathrm{ad}}$ & $\mathrm{H}_{\mathrm{ad}}$ & $\mathrm{O}_{\mathrm{ad}}$ & $\mathrm{N}_{\mathrm{ad}}$ & $\mathrm{S}_{\mathrm{ad}}$ \\
lignite & 46.40 & 3.44 & 16.01 & 0.76 & 0.47 \\
$\begin{array}{c}\text { cotton } \\
\text { stalk }\end{array}$ & 41.16 & 4.96 & 40.58 & 0.92 & 0.16 \\
sawdust & 41.90 & 5.17 & 46.51 & 0.19 & 0.16 \\
\hline
\end{tabular}

\section{The Experimental Results and Analysis}

The analysis of biomass and coal separately pyrolysis:

The pyrolysis process of biomass has been divided into three stages, e.g: moisture precipitation, volatile precipitation and carbonization as same as that of coal. There are large differences in TG curves of biomass and that of coal in Picture 1. Biomass is mainly composed of hemicelluloses, cellulose and lignin. The pyrolysis rate of hemicelluloses and that of cellulose are fast, the start-decomposition temperature of hemicelluloses is mainly $225 \sim 350^{\circ} \mathrm{C}$, and that of cellulose is mainly $325 \sim 375^{\circ} \mathrm{C}$. That of lignin is generally 
250 500 ${ }^{\circ} \mathrm{C}$ [5]. The hemicelluloses and cellulose mainly decompose into volatile substances, but the lignin mainly decomposes into carbon [6].

Those would be found that biomasses maximum weight loss rates are between 250 to 400 degrees Celsius, the maximum weight loss rate of coal is about 450 degrees Celsius. Biomass gasification residue is only about $20 \%$ of the total weight, that is caused by that the biomass has high volatile and the amorphous carbon occupies the main component of flammable carbon. The gasification residue of coal is about $80 \%$ of the total weight, this is because the volatile matter content of coal is lesser than that of biomass, and the amorphous carbon does not occupy the main component of combustible carbon.

By observing the biomass TG curves shown in Picture 1, we also can know that the moisture inside the biomass have been vaporized completely from $50^{\circ} \mathrm{C}$ to $200^{\circ} \mathrm{C}$, large amounts of volatile are produced through by cellulose decomposition in $250 \sim 400{ }^{\circ} \mathrm{C}$, then the pyrolysis process enters the carbonization stage and the curve tended to be gentle after $450^{\circ} \mathrm{C}$. Coal pyrolysis process is more complicated than biomass. With the temperature increasing, moisture and gas in gaps of coal are removed successively (to $350 \sim 400{ }^{\circ} \mathrm{C}$ ); the primary gas be released mainly by depolymerization and decomposition reaction in $\left(400 \sim 550^{\circ} \mathrm{C}\right)$; polycondensation reaction gas and the decomposition gas be released by mineral, also called secondary degassing [7]. The experimental phenomenon and the descriptions of literatures [5] [7] are basic consistent.

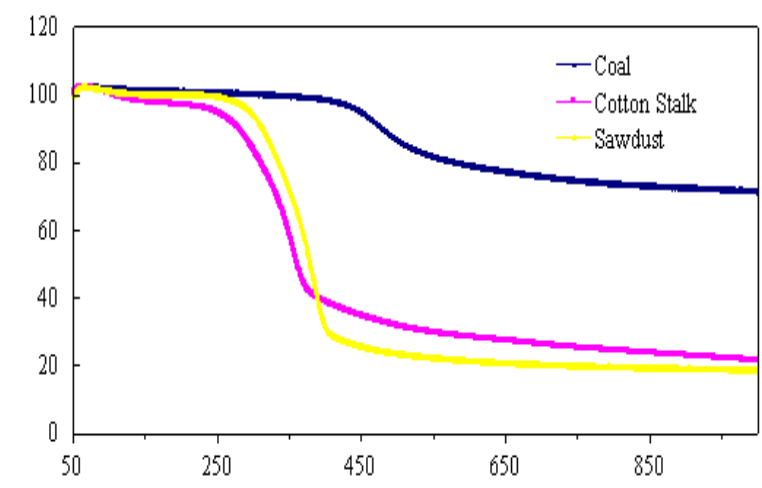

\section{Figure 1. The TG Curve Comparison of Biomass and Coal Separately Pyrolysis}

In order to analysis the interaction of biomass and coal, translate the quality percentage of each temperature point when biomass and coal pyrolysis separately with the weighted average method, then compare with the experimental values. Definition: Difference $=$ Experimental value - Calculated value. When the difference is positive, it exist inhibition in the process of biomass and coal co-pyrolysis; when the difference is negative, it exist acceleration in the process of biomass and coal co-pyrolysis.

$$
m=m_{b} \times \alpha+m_{c} \times \beta
$$

In the formula: $\mathrm{m}$ - the quality percentage of each temperature point has been translated; $\mathrm{mb}$ - the quality percentage of each temperature point when biomass separately pyrolysis; $\mathrm{mc}$ - the quality percentage of each temperature point when coal separately pyrolysis; $\alpha$ the quality percentage of biomass in mixture; $\beta$ - the quality percentage of coal in mixture.

Figure 2, 3 and 4 shows that the difference curves of experimental values and calculated values for cotton stalk and coal co-pyrolysis in the different mixed modes. Figure 5, 6 and 7 shows that the difference curves of experimental values and calculated values for sawdust and coal co-pyrolysis in the different mixed modes. By analysis of curves we can obtain that:

(1) No matter in which mixed mode that existed inhibition in process of cotton stalk and coal co-pyrolysis. The inhibition reached the maximum at about $350^{\circ} \mathrm{C}$. Through the 
TG curve of the cotton stalk separately pyrolysis, we can got that the volatile of cotton stalk began to large amounts of precipitation when the temperature reached $250^{\circ} \mathrm{C}$, the volatile was precipitated completely at $350^{\circ} \mathrm{C}$, and inhibition reached the maximum at the time. The author assume that at this stage, due to the particles fineness of coal is less than that of cotton stalk, it may attach on the cotton stalk, thus it restrain the escape and spread of volatile of cotton stalk. A large number of cotton stalks volatile released makes the pressure increases around coal particles, inhibiting the release of volatile in coal.

(2) When the temperature reached $400{ }^{\circ} \mathrm{C}$, the volatile of coal began to release, inhibition peaked at $460^{\circ} \mathrm{C}$. The reason may be that due to a large amount of volatile separated out from cotton stalk, and the particles pore became big, turned to loose and soften, adhered on the coal pore, and inhibited the precipitation of volatile in coal to some extent. But the inhibition was not very much because the content of volatile in coal was far less than cotton stalk.

(3) When the temperature from $550^{\circ} \mathrm{C}$ to $750{ }^{\circ} \mathrm{C}$, the inhibition was decreasing and turning stable, it was proved that there had acceleration in this temperature. The reason may be due to the inorganic elements $(\mathrm{Ca}, \mathrm{K}$, etc $)$ in the cotton stalk that can promoted the coal pyrolysis to a certain extent, reduced the aliphatic compounds of mixture, increased the number of aromatic compounds, reduce the formation of coke, and promote the precipitation of the volatiles [8].

(4) When the temperature from $750^{\circ} \mathrm{C}$ to $1000^{\circ} \mathrm{C}$, the inhibition increased slowly. When the pyrolysis temperature raised higher than $800^{\circ} \mathrm{C}$, the alkali metals in pyrolysis tar can evaporated off [9], and weakened the promoting effect because the loss of alkali metal; at the same time because of the cotton stalk ash began to melt, covered the surface of coal, blocked the coal pore, the coal pyrolysis had been further suppressed. The inhibition increasing was the combine action of the two factors above.

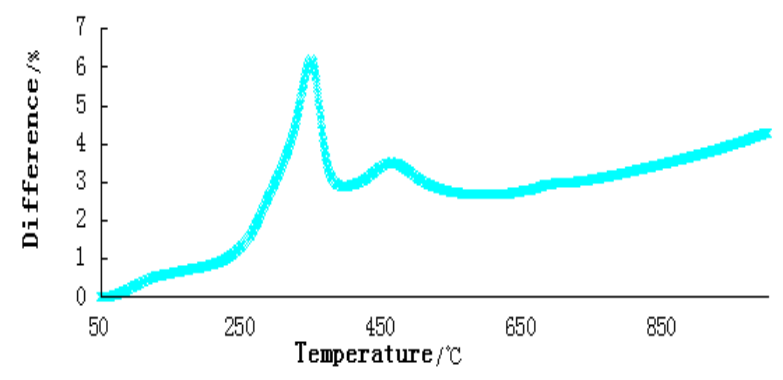

Figure 2. The Difference Curves of Cotton Stalk and Coal Co-Pyrolysis (Uniformly Mixed)

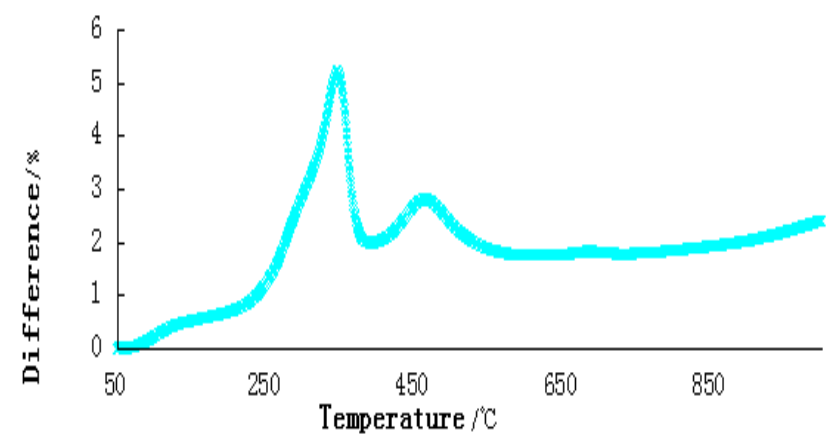

Figure 3. The Difference Curves of Cotton Stalk and Coal Co-Pyrolysis (Coal In The Upper) 


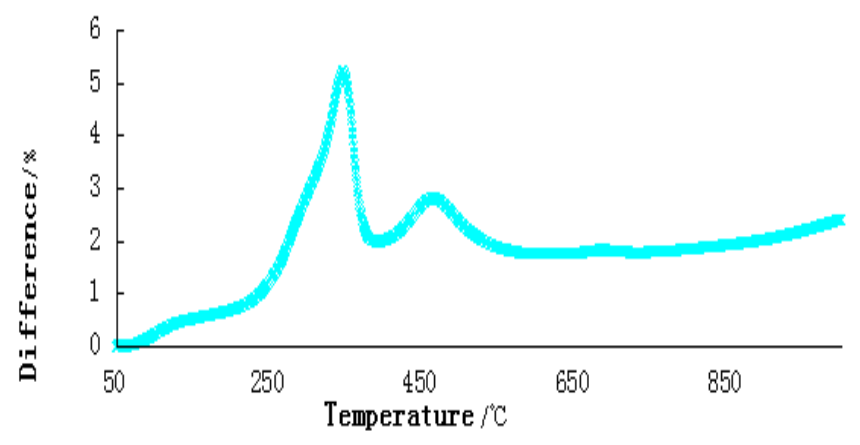

Figure 4. The Difference Curves of Cotton Stalk and Coal Co-Pyrolysis (Biomass in the Upper)

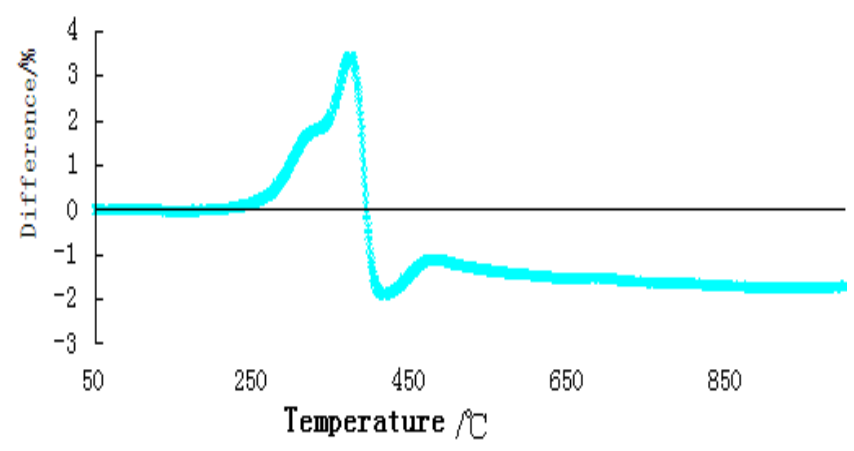

Figure 5. The Difference Curves of Sawdust and Coal Co-Pyrolysis (Uniformly Mixed)

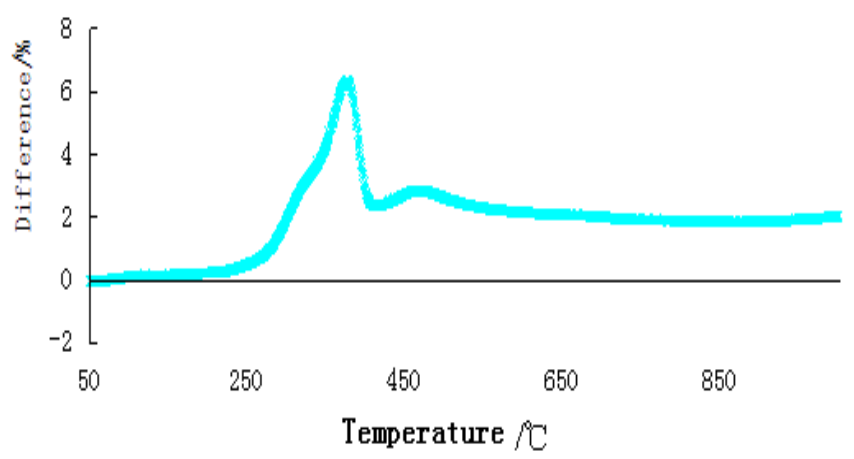

Figure 6. The Difference Curves of Sawdust and Coal Co-Pyrolysis (Coal in the Upper) 


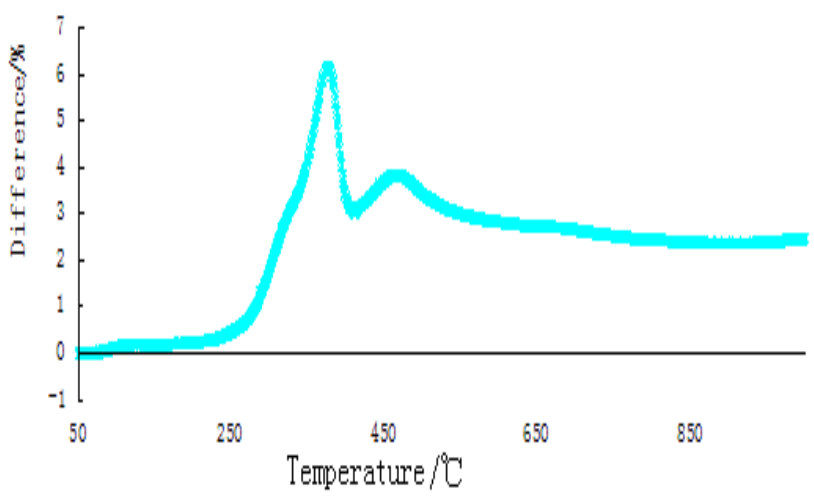

\section{Figure 7. The Difference Curves of Sawdust and Coal Co-Pyrolysis (Biomass in the Upper)}

The studies on the biomass and lignite co-pyrolysis of Hongxiang $\mathrm{Wu}$ showed that the alkali / alkaline metal elements compounds can accelerate the coal pyrolysis reaction velocity at the low temperature, and silicon inhibitory effect on the pyrolysis rate of coal, at the same time that $\mathrm{K}$ is the main catalyst to promote coal pyrolysis reaction velocity at low temperature. But in the thermo gravimetric experiment, the alkali/alkaline metal element compounds of the biomass cannot full contact with the coal, so all promotion affects not did not appear obviously. At the high temperature, the alkali/alkaline metal element would vapour with the alkali metal oxide form and the alkali metal chloride form. So at the high temperature, all promotion affects not did not appear also except the copyrolysis of coal and sawdust. The alkali/alkaline metal element of sawdust exit in the form of sulfate. The alkali/alkaline sulfate can exit in the solid or liquid form at high temperature. So in the co-pyrolysis of coal and sawdust, there is obvious promotion affect. The co-pyrolysis experiments of lignite and biomass by Weiping Yan showed that the copyrolysis reaction of biomass and coal is affected by the biomass mineral composition and characteristics, coal ash composition and characteristics [10]. That the co-pyrolysis interaction of coal and biomass is promotion or inhibition depends on many factors. When the biomass content exceeds 50\%, large amounts of biomass would soften and melt when the coal is devolatilizing. They would cover the coal surface and block the coal particles pores, at last inhibit the evolution and diffusion of coal volatile, so if the biomass content exceeds $50 \%$, the inhibition interaction would appear.

Wenkui Zhu [11] by bituminous coal and wheat straw pyrolysis experiments show that alkali metal salts, gasification of coal and water vapor and $\mathrm{CO} 2$ has a catalytic effect, especially potassium. And co-pyrolysis of coal and straw to produce mixed coke reactivity and carbon conversion rate than coal and coke, activity at $750^{\circ} \mathrm{C}$ prepare mixed coke and alkaline substance concentration is the highest. Li Zhang fell out of bed the pyrolysis experiment in free by coal and Beanstalk that under atmospheric pressure, coal and Beanstalk synergistic effect, and when the proportion of corn stalk reaches $70 \%$, the prepared hybrid focal activity are bigger than those of coal and biomass char. That Yang Yili by coal and biomass gasification experiments of biomass increased content, add in the style of $\mathrm{K}, \mathrm{Ca}$ have catalytic effect of material, promoting the gasification reaction, activation energy decrease, increase the reaction activity of mixed coke. Ma Lin through the experimental study of two steps of lignite and biomass showed that biomass, pyrolysis atmosphere can promote the coal pyrolysis, pyrolysis temperature and residence time of material of lignite and biomass pyrolysis effect has a certain improving effect. Li Shiguang[12] indicated that the co-pyrolysis had certain synergistic effect in free fall test bed fast pyrolysis of the coal and biomass, especially at high temperature $\left(800^{\circ} \mathrm{C}\right)$, high mixing ratio (such as $75 \%$ ) and high rank coal is more obvious. Based on the study of 
sulfur pyrolysis migration also indicated that the reaction temperature is higher $\left(800^{\circ} \mathrm{C}\right)$, add a small amount of biomass for heat release sulfur coal production of sulfur, and the rapid pyrolysis of coal, there is serious to inorganic sulfur transformation reaction of organic sulfur. Foreign scholar M. Yilgin by lignite and beet 1:1 ratio of fast pyrolysis experimental research show that, there is a synergetic effect of pyrolysis of lignite and beet, and at $600{ }^{\circ} \mathrm{C}$ the prepared hybrid focal activity of large. Add $10 \%$ hazelnut shell of different rank coal thermal gravimetric analyzer with H.Haykiri Acma after pyrolysis experiments, the results show that the addition of hazelnut shell of coals of different volatile reaction in low removal, a greater impact on the char yield of lignite, proved its thermal solutions of certain synergistic effect exists in the process. K.Sjostrom [13] and other woody biomass and coal gasification in pressurized fluidized bed in the experimental, results show that the reaction activity of mixed coke has higher, and the decreased mixing coke and ammonia yield is affected by the synergistic effect.

In the process of reactive power compensation, the hybrid transformer and parallel capacitor group are used together. When the magnetizing current is zero, hybrid device works in the state of transformer. When the magnetizing current of hybrid device is a rated value, it works in the state of the controllable reactor. Under normal circumstance, the magnetizing current is between of zero and a rated value, so it has the function of transformer and controllable reactor.

Reaction kinetics is the study of reaction mechanisms and rate of chemical reactions. By kinetic analysis provides insight into the process and mechanism of the reaction, analyzing the temperature, heating rate and other parameters influence the conversion rate of the reaction products or materials [14].

Kinetic basic formula used in this paper is:

$$
\frac{d \alpha}{d T}=f(\alpha) k(T)
$$

According to Arrhenius equation:

$$
k=A \exp \left(-\frac{E}{R T}\right)
$$

The $\alpha$ in formula (1) is carbon conversion rate during the reaction, to satisfy the following formula:

$$
\alpha=\frac{m_{0}-m}{m_{0}-m_{\infty}}
$$

In formula (3): $m_{0}$ - Initial quality; $m$ - quality in time T; $m_{\infty}$ - Termination quality. The form of $f(\alpha)$ depends on of the type of reaction, the gasification reaction of carbon is regarded as the first order reaction, so: $f(\alpha)=1-\alpha$. Set heating rate is $\beta$ (constant), by the formula (1) and (2) to give:

$$
\frac{d \alpha}{d T}=\frac{A}{\beta} \exp \left(-\frac{E}{R T}\right)(1-\alpha)
$$

On both sides of the integrals:

$$
-\ln (1-\alpha)=\frac{A}{\beta} \int_{T_{0}}^{T} \exp \left(-\frac{E}{R T}\right) d T
$$


Introducing a function of temperature $P(y)=\int_{y}^{\infty} \frac{e^{-y}}{y^{2}} d y$, in formula $y=\frac{E}{R T}$, equation (5) can be simplified as:

(6)

$$
-\ln (1-\alpha)=\frac{A E}{\beta R} P(y)
$$

Treatment of the formula (6) with Coats-Redfern Method:

$$
\ln \left[-\frac{\ln (1-\alpha)}{T^{2}}\right]=\ln \left(\frac{A R}{\beta E}\right)-\frac{E}{R T}
$$

(7)

Plot for $1 / \mathrm{T}$, then the linear regression, the linear equation:

$$
f\left(\frac{1}{T}\right)=-\frac{E}{R} \frac{1}{T}+\ln \left(\frac{A R}{\beta E}\right)
$$

Figure 8 and 9 are the $1 / \mathrm{T}-\mathrm{f}(1 / \mathrm{T})$ relationship in pyrolysis process of biomass and coal. The slope of this line is to obtain the reaction activation energy $\mathrm{E}$. The $\mathrm{E}$ is higher shows activity weaker, whereas the activity is stronger. The results are shown in Table 3 and 4. From Table 3 and 4, each fitting equation correlation coefficients greater than 0.99, indicating the linear regression reasonable.

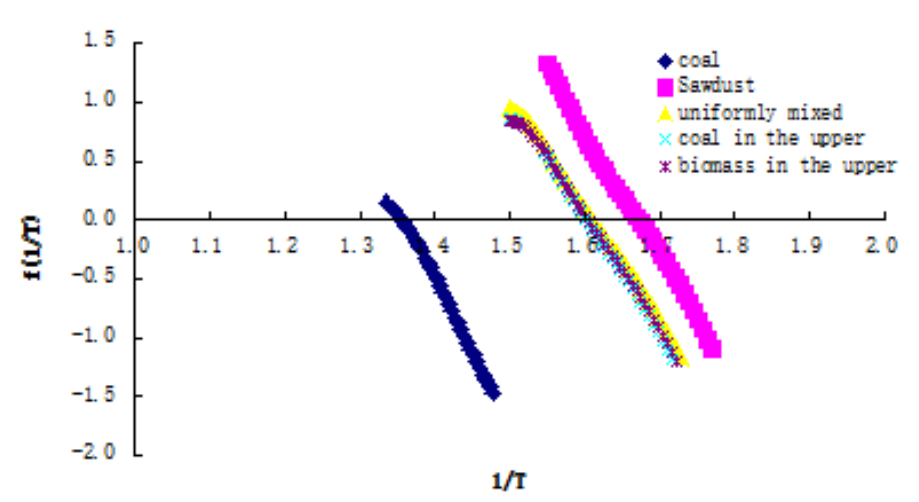

Figure 8. 1/T - F (1/T) Relationship in Pyrolysis Process Of Sawdust And Coal

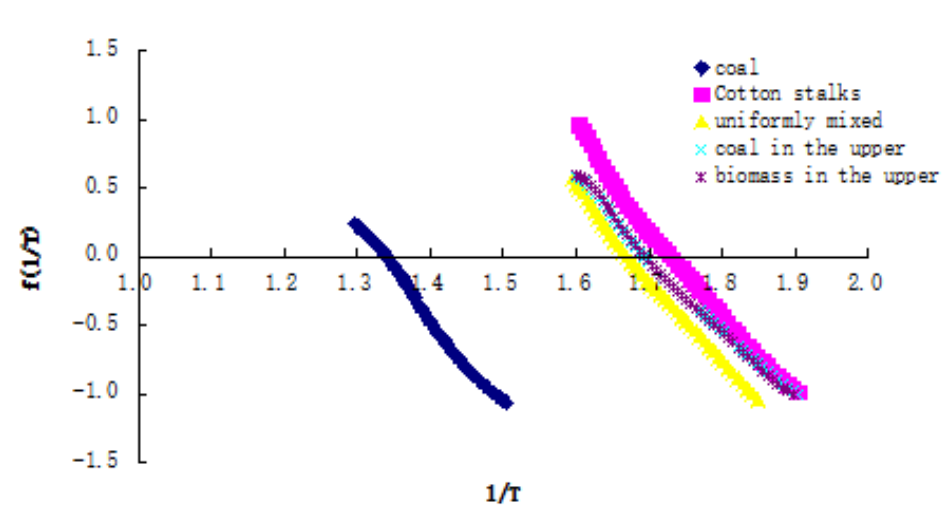

Figure 9. 1/T - F (1/T) Relationship in Pyrolysis Process of Cotton Stalks and Coal 
Table 3. The Activation Energy of Coal and Sawdust

\begin{tabular}{ccc}
\hline Sample & $\mathrm{E}(\mathrm{kJ} / \mathrm{mol})$ & $\mathrm{R}^{2}$ \\
\hline Coal & 98.56 & 0.9943 \\
\hline Sawdust & 86.87 & 0.9970 \\
\hline $\begin{array}{c}\text { uniformly } \\
\text { mixed }\end{array}$ & 78.20 & 0.9977 \\
\hline $\begin{array}{c}\text { coal in the } \\
\text { upper }\end{array}$ & 80.08 & 0.9970 \\
\hline $\begin{array}{c}\text { biomass in the } \\
\text { upper }\end{array}$ & 78.70 & 0.9959 \\
\hline
\end{tabular}

Table 4. The Activation Energy of Coal and Cotton Stalks

\begin{tabular}{ccc}
\hline Sample & $\mathrm{E}(\mathrm{kJ} / \mathrm{mol})$ & $\mathrm{R}^{2}$ \\
\hline Coal & 56.92 & 0.9938 \\
\hline Cotton stalks & 53.18 & 0.9934 \\
\hline $\begin{array}{c}\text { uniformly } \\
\text { mixed }\end{array}$ & 51.64 & 0.9960 \\
\hline $\begin{array}{c}\text { coal in the } \\
\text { upper }\end{array}$ & 44.19 & 0.9926 \\
\hline $\begin{array}{c}\text { biomass in the } \\
\text { upper }\end{array}$ & 46.03 & 0.9937 \\
\hline
\end{tabular}

\section{Conclusions}

The following conclusions can be got by the above researches.

(1) There are large differences in TG curve between the separately pyrolysis of biomass and coal. The beginning pyrolysis temperature of biomass is lower than coal; the weight loss rate of biomass is faster than coal; the eventually weightlessness rate of biomass is greater than coal.

(2) In the process of biomass (cotton stalk and sawdust) and coal co-pyrolysis, the inhibitory effect of them both peaked at about $3500^{\circ} \mathrm{C}$, and reached the second peak at about $460{ }^{\circ} \mathrm{C}$. The interaction was not obvious between before $250^{\circ} \mathrm{C}$ and after $550^{\circ} \mathrm{C}$.

(3) There are effects of promotion and inhibition in process of biomass and coal copyrolysis. The competition of the two sides of effects leads to the different results. No matter in which mixed mode, that existed the inhibition in process of cotton stalk and coal co-pyrolysis; when the temperature exceeded $400{ }^{\circ} \mathrm{C}$, the result showed the mutual promotion effect in the process of sawdust and coal co-pyrolysis. Because of the content of volatile, ash and alkali metal in cotton stalk and sawdust is different, lead to the result of interaction is different. The content of volatile and alkali metal in sawdust is higher than cotton stalk; it is contribute to pyrolysis of coal. At the same time the content of ash in sawdust is less than cotton stalk, lead to the ratio of adhesion on coal pores decreases. Thus the promotion effect is stronger than inhibition effect when sawdust and coal copyrolysis in mode of uniform mixed.

(4) Because of the different compositions of biomass and the different methods of mix, the pyrolysis characteristics are diverse. The current experiment is only preliminary study; we can make the interaction of biomass and coal co-pyrolysis turn to positive through changing the experimental conditions in future. 


\section{Acknowledgments}

The paper was supported by Shenyang Municipal Science and Technology Bureau Project (No. F11-005-2-00).

\section{References}

[1] H. B. Vuthaluru, "Thermal behavior of coal/biomass blends during co-pyrolysis". Fuel Processing Technology, vol. 85, no. 187, (2004).

[2] A. G. Collot, Y. Zhuo and D. R. Dugwell, "Co-Pyrolysis and Co-Gasification of Coal and Biomass in Bench-Seale Fixed-Bed and Fluidized Bed Reactors", vol. 78, no. 667, (1999).

[3] K. Z. Li, R. Zhang and J. C. Bi, "Chemical Reaction Engineering and Technology", vol. 24, no. 312, (2008).

[4] R. C. Brown, Q. Liu and G. Norton, "Catalytic Effects Observed during the Co-Gasification of Coal and Switchgrass", Biomass and Bioenergy, vol. 18, no. 499, (2000).

[5] H. M. Yang, C. L. Han and Y. P. Wu, Journal of college of science, vol. 28, no. 56, (2008).

[6] P. Wang and F. Wen. Coal Conversion, vol. 31, no. 40, (2008).

[7] L. Q. Song and M. Zhou, "Chinese Agricultural Mechanization, vol. 4, no. 114, (2011)

[8] C. A. Ulloa, A. L. Gordon and X. A. Garca, "Thermogravimetric study of interactions in the pyrolysis of blends of coal with radiate pine sawdust “, Fuel Processing Technology, vol. 90, no. 583, (2009).

[9] J. Bai, W. Li and C. Z. Li, "Influence of coal blending on mineral transformation at high temperatures", Mining Science and Technology, vol. 19, no. 300, (2009).

[10] W. P. Yan and Y. Y. Chen, Proceeding of the CSEE, vol. 27, no.50, (2007).

[11] W. K. Zhu and W. L. Song, "Study of catalytic gasification of co-pyrolysis char derived from coal and K-riched biomass", Journal of China University of Mining \& Technology, vol. 40, no.616, (2011).

[12] S. G. Li and S. P. Xu, "co-pyrolysis of coal and biomass", Coal Conversion, vol. 25, no.7, (2002).

[13] K. Sjostrom and G. Chen, "Promoted reactivity of char in co-gasification of biomass and coal: synergies in the thermochemical process", Fuel, vol. 78, no.1189, (1999).

[14] F. F. Yan and Y. D. Zhu, "Thermal Gravimetric Analysis on Co-gasification Characteristics of Biomass and Coal Blends", Energy Technology, vol. 30, no. 205, (2009).

[15] K. D. Zhang and X. P. Bu, "Experimental study on co-gasification of biomass and coal in an atmosphere of $\mathrm{CO} 2 "$.

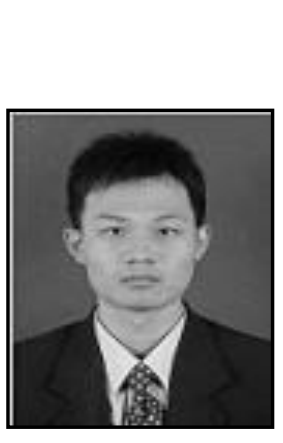

\section{Authors}

Jia Hao was born in 1989, at Dingzhou, hebei province. He received master graduate of power engineering in Shenyang Institute of Engineering. His research direction is research of mixed with coal gasification of biomass.

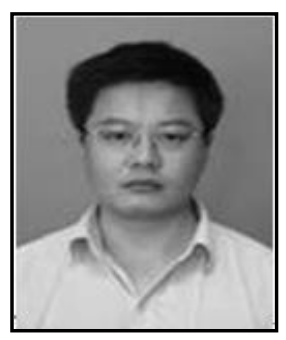

Qimin Wang, Professor of Shenyang Institute of Engineering, graduated from the Department of thermal engineering at Tsinghua University. The studies are focused on the biomass boilers, the industrial boilers and clean coal technologies. 